\title{
Operando studies of iodine species in an advanced oxidative water treatment reactor
}

\author{
Ahmed Moustafa, ${ }^{1}$ Alex Evans, ${ }^{1}$ Simmon Hofstetter, ${ }^{1}$ Jenny Boutros, ${ }^{1}$ Parastoo \\ Pourrezaei, ${ }^{1}$ Cheng Zhang, ${ }^{1}$ Laura Patterson-Fortin, ${ }^{1}$ Charles Laing, ${ }^{1}$ Carter Goertzen, ${ }^{1}$ \\ Richard Smith, ${ }^{1}$ Kenneth R. Code, ${ }^{1}$ Ning Chen, ${ }^{2}$ Peter E. R. Blanchard, ${ }^{2}$ Nathan \\ Bettman, ${ }^{3}$ Raquibul Alam, ${ }^{3}$ Kerry McPhedran, ${ }^{3}$ Zohreh Fallah, ${ }^{4}$ Edward Roberts, ${ }^{4}$ and \\ Michael W. Gaultois ${ }^{5, a)}$ \\ ${ }^{1)}$ BioLargo Water Inc., Agrifood Discovery Place, Edmonton, AB T6H 2V8, \\ Canada \\ ${ }^{2)}$ Canadian Light Source, Saskatoon, SK S7N 2V3, Canada. \\ 3) Department of Civil and Geological Engineering, University of Saskatchewan, \\ Saskatoon, SK S7N 5A9, Canada \\ 4) Department of Chemical and Petroleum Engineering, University of Calgary, Calgary, \\ $A B$ T2N 1N4, Canada \\ 5)Leverhulme Research Centre for Functional Materials Design, \\ The Materials Innovation Factory, Department of Chemistry, \\ University of Liverpool, 51 Oxford Street, Liverpool, L7 3NY, \\ United Kingdom
}

(Dated: 19 January 2021) 
We present an electrochemical advanced oxidation process (eAOP) reactor employing expanded graphite, potassium iodide (KI), and electrical current, which demonstrates an exceptionally high rate of inactivation of $E$. coli $\left(6 \log _{10}\right.$ reduction in viable cells) at low current density $\left(0.6 \mathrm{~mA} / \mathrm{cm}^{2}\right)$, with low contact time (5 minutes) and low concentration of KI (10 ppm). Operando X-ray fluorescence mapping is used to show the distribution of iodine species in the reactor, and operando X-ray absorption spectroscopy in the anodic chamber reveals iodine species with higher effective oxidation state than $\mathrm{IO}_{4}{ }^{-}$. Operando electrochemical measurements confirm the conditions in the anodic chambers are favourable for the creation of highly oxidized iodine products. The killing efficiency of this new eAOP reactor far exceeds that expected from either traditional iodine-based electrochemical water treatment or advanced oxidation systems alone, a phenomenon that may be associated with the production of highly oxidized iodine species reported here.

Keywords: KEYWORDS

a)Electronic mail: m.gaultois@liverpool.ac.uk 


\section{INTRODUCTION}

Access to potable water is crucial for human life, and water security is becoming increasingly important across the world. In an effort to lessen the burden on fresh water sources, significant efforts have been made to promote the development and use of effective and cost-efficient wastewater treatment and reuse technologies. Advanced Oxidation Processes (AOPs) are emerging as a promising class of technologies for treatment of industrial and municipal waste streams for removal of recalcitrant contaminants including pharmaceuticals, pesticides, and industrial chemicals, a key facet of wastewater treatment. AOPs function by in situ generation of strong oxidants through a two-step process to destroy contaminants, first generating reactive oxidants and radicals that in turn react with target contaminants..$^{112}$ The major oxidant involved is the hydroxyl radical $\left({ }^{\bullet} \mathrm{OH}\right)$, a strongly oxidizing species that reacts non-selectively with organic compounds. Its short lifespan in water ensures any reactions are self-limiting. ${ }^{1 / 3+5}$ AOPs can be broadly classified as ozone- or UV-based, electrochemical, catalytic, and physical. ${ }^{[16}$ Full-scale processes have been established for ozone-based, UV-based, and catalytic AOPs whereas electrochemical and physical methods have been investigated exclusively at the lab- and pilot-scale. ${ }^{2}$

Electrochemical AOPs (eAOPs) electrolytically produce ${ }^{\bullet} \mathrm{OH}$ and other oxidants to effect treatment of water ${ }^{[17}$ The simplest eAOP is direct anodic oxidation whereby ${ }^{\bullet} \mathrm{OH}$ is produced at the surface of an electrode through the oxidation of water ${ }^{8}$ Contaminants are destroyed through a combination of (1) direct oxidation of contaminants at the surface of the electrode, ${ }^{9-11}$ (2) indirect oxidation in solution from ${ }^{\circ} \mathrm{OH}$ generated, ${ }^{[12}$ and (3) electric field effects. ${ }^{13}$ Alternatively, indirect eAOPs require external addition of or in situ generation of additional reagents that react to produce hydroxyl radicals. For example, eAOPs based on Fenton's chemistry (electro-Fenton and photoelectron-Fenton) use the reaction between $\mathrm{H}_{2} \mathrm{O}_{2}$ and $\mathrm{Fe}^{2+}$ to produce ${ }^{\bullet} \mathrm{OH} \cdot{ }^{[4115}$ Oxidation may also be mediated by electrochemical generation of strong oxidants generated at the anode from ions in bulk solution $^{114}$ including halides like chlorine species ${ }^{16}-18$ and iodine species. ${ }^{1920}$

In addition to destruction of organic contaminants, inactivation of bacteria, viruses (bacteriophages) and algae using eAOPs has been demonstrated. ${ }^{21+25}$ eAOPs also have demonstrated effectiveness for mineralization of numerous organic compounds, and the mechanism of their action is relatively well-understood with respect to the advanced oxi- 
dation component of eAOPs. Radicals produced through advanced oxidation rapidly react with organic compounds via electron transfer, dehydrogenation, or hydroxylation producing organic radicals which, through the resulting radical oxidation chain, produce $\mathrm{CO}_{2}$ and $\mathrm{H}_{2} \mathrm{O} \cdot{ }^{26127}$ In contrast to advanced oxidation, the exact mechanisms of disinfection and decontamination by the electrochemical component of eAOPs are less well-understood, a problem attributed to the broad range of cellular components that can be damaged by oxidizing and reducing agents alike. Damage caused by oxidative compounds generated through electrolysis can occur to cell surfaces (cell wall, cell membrane or spore coat) and/or to cellular components (DNA, protein, lipids)! ${ }^{1328}$ Evidence suggests that the mechanism of disinfection by eAOPs is likely a function of the type of anode used ${ }^{13}$ and the identity of any halides or other electrochemically relevant compounds in the input water.

Some advantages of eAOPs include: the ability to address multiple different contaminant classes, a generally high disinfection efficiency, in situ production of reactive chemical species, amenability to automation, and ease of treatment input control. ${ }^{[1612729}[31]$ Despite these advantages, economic and technical concerns have limited large-scale implementation of these technologies, including mass transfer limitations which lead to reduced disinfection performance, low conductance of most wastewater, limited lifespan due to fouling of the electrodes, potential accumulation of oxidation refractory intermediates, and high electricity costs. $.362732,35$

An Edmonton, Alberta-based water treatment technology company, BioLargo Water, has developed an electrochemical advanced oxidation process for treatment of water termed the "Advanced Oxidation System" (AOS). The AOS is a carbon-based packed-bed electrochemical water treatment system that uses expanded graphite as its electrode bed material, iodide as its principle electrochemically active input chemical, and a proprietary spacer to separate electrodes within the device. While the geometry is flexible, the device typically has 6 serial chambers ( 3 cathodes and 3 anodes), and is designed this way to provide multiple instances of bactericidal action for water passing through it (Figure 1a).

The AOS uses iodine as its input chemical to drive disinfecting oxidation reactions at the anodic chamber. Iodine is a strong oxidant and long-studied disinfectant; when exposed to bacteria, iodine interferes with bacterial cellular function by oxidizing or iodinating proteins, nucleotides of DNA or RNA, or fatty acids, ultimately leading to cell death.1936-38 While molecular iodine $\left(\mathrm{I}_{2}\right)$ is generally thought to be the principle species of iodine re- 


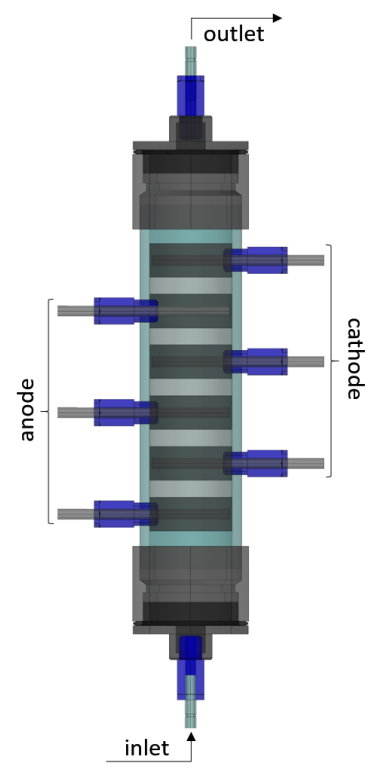

(a)

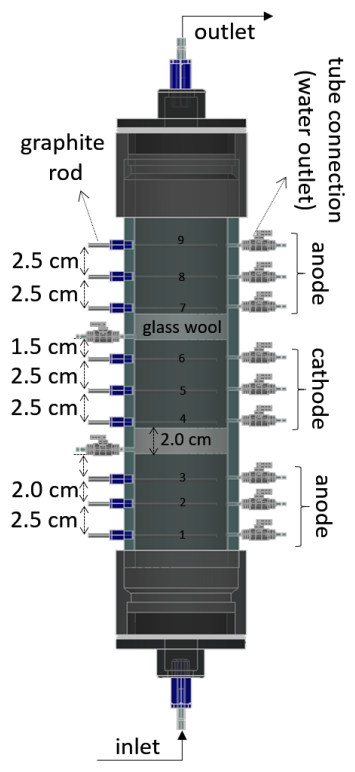

(b)

FIG. 1: (a) The AOS reactor is a carbon-based packed-bed electrochemical water treatment system that uses expanded graphite as its electrode bed material, iodide as its principle electrochemically active input chemical, and a proprietary spacer to separate electrodes within the device. While the geometry is flexible, the device typically has 6 serial chambers ( 3 cathodes and 3 anodes), and is designed this way to provide multiple instances of bactericidal action for water passing through it. An unmodified AOS reactor is used for the operando spectroscopic measurements presented here. (b) To measure the distribution of electrical potential during operation of the reactor, a modified AOS reactor was constructed, and is used for the operando electrochemical measurements presented here.

sponsible for bacterial inactivation, hypoiodous acid (HOI) and periodate $\left(\left[\mathrm{IO}_{4}\right]^{-}\right)$are also known to exhibit bactericidal properties. ${ }^{1936137}$ The AOS, by virtue of its design, also contains a cathodic cell that reduces electro-generated oxidizing agents back to halide ions, minimizing release of active chemicals into the treated water. ${ }^{[16}$ This trait grants the AOS an advantage in that it has lower risk of emitting active chemicals and byproducts into the environment, but it also means the device does not output residual disinfectants, which could be a downside in some applications.

In this study we present an electrochemical reactor capable of disinfection with high 
kill efficiency, short contact times, low current, and low concentrations of active species. Using the BioLargo AOS, we demonstrate 1) disinfection in a carbon-based packed-bed electrochemical water treatment system, and 2) novel electrochemical species generated by this specific proprietary water treatment device (the AOS). The killing efficiency of this new electrochemical reactor exceeds that expected from either iodine-based electrochemical disinfection or from other advanced oxidation processes. The mechanism of this synergistic activity is hypothesized to be associated with the production of highly oxidized iodine species observed in this study.

\section{METHODS}

\section{A. Microbiological studies}

Escherichia coli MC4100, a common strain of K12, was used in this study. Bacterial cultures were grown in Luria-Bertani (LB) medium at $37^{\circ} \mathrm{C}$ and aerated by shaking at $150 \mathrm{rpm}$. Overnight cultures were harvested and resuspended in $5 \mathrm{~L}$ reverse osmosis (RO) water. Potassium iodide (KI; $10 \mathrm{ppm}$ or $50 \mathrm{ppm}$ ) was added where indicated.

Inactivation of $E$. coli using the AOS technology was performed using a 2" 6-chamber reactor packed as described above. RO water seeded with $\sim 10^{8} \mathrm{CFU} / \mathrm{mL}$ E. coli was passed through the AOS reactor at $80 \mathrm{~mL} / \mathrm{min}$ under the following conditions: $0 \mathrm{~V}, 0 \mathrm{ppm} \mathrm{KI} ; 6 \mathrm{~V}$, $0 \mathrm{ppm} \mathrm{KI}$; and 6V, $10 \mathrm{ppm} \mathrm{KI}$. Samples were collected at 10 minute intervals for a total of 60 minutes. The number of viable $E$. coli cells after treatment was determined by spiral plating $50 \mu \mathrm{L}$ aliquots on LB agar. To clean the reactor prior to each experiment, the reactor was flushed with $30 \mathrm{ppm} \mathrm{KI}$ at $80 \mathrm{~mL} / \mathrm{min}$ under $6 \mathrm{~V}$ electrical potential for 30 minutes. The electrical polarity was then inverted for 15 minutes without flow, after which time the reactor was then flushed with RO water for 30 minutes at $80 \mathrm{~mL} / \mathrm{min}$. This flushing protocol was also repeated after each experiment.

To identify where disinfection occurs, RO water seeded with $\sim 10^{8} \mathrm{CFU} / \mathrm{mL}$ E. coli was passed through a horizontal 1", 2-chamber glass reactor at $20 \mathrm{~mL} / \mathrm{min}, 12 \mathrm{~V}$ for $60 \mathrm{~min}$ utes. The horizontal orientation allowed bacteria to pass through either the anodic or cathodic chamber but not both. Samples were collected at 15 minute intervals for a total of 60 minutes. The number of viable $E$. coli cells after passage through the anodic or 
cathodic chambers were determined by spiral plating $50 \mu \mathrm{L}$ aliquots on LB agar. Prior to each experiment, the reactor was flushed with $\mathrm{RO}$ water for 30 minutes at $20 \mathrm{~mL} / \mathrm{min}$. After each experiment, the reactor was cleaned by flushing with $50 \mathrm{ppm}$ KI solution for 120 minutes at $20 \mathrm{~mL} / \mathrm{min}$ under $12 \mathrm{~V}$ applied potential, with a reversed bias after 60 minutes.

\section{B. Operando I K edge X-ray spectroscopy}

Measurements were performed at the HXMA beamline at the Canadian Light Source. ${ }^{39}$ The beamline energy for the I K-edge at $33169 \mathrm{eV}$ was calibrated to the Sb K-edge at $30491 \mathrm{eV}$ using Sb foil collected in transmission geometry; ion chambers were filled with $5 \% \mathrm{Ar}$ and $95 \% \mathrm{~N}_{2}$. All data of solutions presented in this work was collected in fluorescence geometry using the 32-element Ge detector, as absorption through the diameter of the reactor leads to a weak transmission signal.

A motorized stage was used to control the position of the reactor with respect to the X-ray beam. X-ray fluorescence (XRF) maps were collected using an X-ray beam of dimensions $2 \mathrm{~mm} \times 1 \mathrm{~mm}$ (width $\times$ height); the reactor was mapped with a $2 \mathrm{~mm} \times 2 \mathrm{~mm}$ spatial grid, with a 2 second dwell time per grid point.

X-ray absorption near edge structure (XANES) measurements were collected using an $\mathrm{X}$-ray beam of dimensions $3 \mathrm{~mm} \times 1 \mathrm{~mm}$. A wider beam was used to improve the signal and decrease the influence of any inhomogeneity in the reactor. Data was collected from $-100 \mathrm{eV}$ to $-40 \mathrm{eV}$ at $5 \mathrm{eV}$ steps, $-40 \mathrm{eV}$ to $50 \mathrm{eV}$ at $1 \mathrm{eV}$ steps, and $50 \mathrm{eV}$ to $7 k$ at $0.1 k$ steps, with dwell times of 2 seconds in each region, resulting in a scan time of $\sim 10$ minutes. At least 2 scans were collected for each measurement to ensure reproducibility. Data was analyzed using the ATHENA software package.40

$1000 \mathrm{ppm}(6 \mathrm{mM})$ standard solutions of reference compounds were prepared by dissolving solid powders in appropriate amounts of deionized water $(18.2 \mathrm{M} \Omega \mathrm{cm})$, or hexanes for $\mathrm{I}_{2}$. Solid reference samples were prepared by finely grinding a compound of interest in an agate mortar and pestle, then diluted by grinding together with boron nitride, and packed to create a solid with appropriate absorption at the I K edge. XANES data collection of solids was performed in transmission geometry, and spectral features are consistent with fluorescence spectra of the corresponding $1000 \mathrm{ppm}$ solutions made by dissolving the solids in water. 
Iodine species are known to transform, so to ensure there was no unintentional evolution of iodine species over time, standards were examined again 24 hours after initial preparation and data collection; no differences were seen in any X-ray spectral features, indicating the species examined here undergo no significant transformation without intentional perturbation over the experimental timelines in this study.

\section{Ex situ cyclic voltammetry}

To determine the electrochemical characteristics of the expanded graphite (EG) used in the AOS reactor, cyclic voltammetry (CV) experiments were performed. Pellet electrodes were prepared by compressing samples of EG using a compression molder. The prepared pellets, with a fixed density, were used as the working electrode. A platinum wire was used as the counter electrode and a silver/silver chloride $(\mathrm{Ag} / \mathrm{AgCl}$ in saturated $\mathrm{KCl})$ was used as a reference electrode. An Autolab PGSTAT 302N potentiostat was used to carry out the cyclic voltammetry experiments with a potential window of $0.0 \mathrm{~V}$ to $1.0 \mathrm{~V}$ and a scan rate of $0.01 \mathrm{~V} \mathrm{~s}^{-1}$. The background electrolytes used used in all $\mathrm{CV}$ measurements were $0.1 \mathrm{M}$ phosphate buffer ( $\mathrm{pH}$ 7.6) and $0.1 \mathrm{M} \mathrm{Na}_{2} \mathrm{SO}_{4}$ ). Potassium iodide solutions were prepared using deionized water, with $100 \mathrm{ppm} \mathrm{KI}(0.6 \mathrm{mM})$ in addition to the background electrolyte.

\section{Operando potential distribution measurement}

A cylindrical AOS reactor with two anodes and one cathode was designed for potential distribution studies (Figure 1b). The potential in the EG bed was measured using graphite rods inserted into the cell at different positions, and external $\mathrm{Ag} / \mathrm{AgCl}$ reference electrodes connected to the solution via capillary tubes was used to measure the solution potential.

An Autolab PGSTAT 302N potentiostat was used to apply a constant voltage and monitor the current during the process. Graphite rods at position 1 and 9 were used as the anode current feeders connected to the potentiostat, and the rod at position 5 was used as the cathode current feeder. The local potential of the EG relative to the $\mathrm{Ag} / \mathrm{AgCl}$ reference electrode at different locations in the EG electrodes (position 7, 8 and 9) and the cathode (position 4, 5 and 6) was measured during operation using a high impedance 
digital voltmeter, while a cell potential of $10 \mathrm{~V}$ was applied between the anodes and the cathode. Potential measurements in the AOS reactor were carried out with a solution feed composition of $0.6 \mathrm{mM} \mathrm{KI}(100 \mathrm{ppm})$ and $28 \mathrm{mM} \mathrm{Na}_{2} \mathrm{SO}_{4}(0.4 \mathrm{wt} . \%)$. Using a cell voltage of $10 \mathrm{~V}$, the total current was $9.42 \pm 0.01 \mathrm{~mA}$. The flow rate of the solution was fixed at $100 \mathrm{~mL} / \mathrm{min}$ using a peristaltic pump.

\section{RESULTS AND DISCUSSION}

\section{A. Rapid disinfection of model bacteria}

To study the mechanism of disinfection that occurs in the AOS reactor, a series of experiments were designed to evaluate the influence of: potassium iodide, electrical potential, and expanded graphite on bacterial disinfection performance. AOS disinfection experiments were performed for 1 hour using RO water seeded with $\sim 10^{8} \mathrm{CFU} / \mathrm{mL}$ E. coli. The number of $E$. coli in the influent and effluent were quantified using total plate counts on LB agar. At the beginning of each experiment, similar levels of $E$. coli were detected in the influent. In the presence of $10 \mathrm{ppm} \mathrm{KI}$ and $6 \mathrm{~V}$, E. coli counts decreased below the quantification limit $(\mathrm{LoQ}=2.6)$ within 10 minutes, representing an approximate $6 \log _{10}$ reduction (Figure 2a). In contrast, in the absence of $\mathrm{KI}$ but the presence of $6 \mathrm{~V}$, no significant decrease in E. coli numbers in the treated effluent was observed (Figure 2b). Similarly, in the absence of both KI and power, no significant decrease in bacteria was observed (Figure 2c). Taken together, these results indicate that both potassium iodide and electrical potential are required for inactivation of bacteria in water using the AOS technology.

Iodine oxidants electrochemically generated within the AOS are thought to be the molecules principally responsible for disinfection within the device. In keeping with this theory, the minimal rates of bacterial inactivation observed in the absence of potassium iodide but in the presence of electrical potential suggests the observed decrease in $E$. coli counts cannot be attributed to electrochemically generated hydroxyl radicals and/or direct oxidation at the anode surface. Similar results have been found for electrochemical disinfection using a range of electrodes including boron-doped diamond (BDD) and tin-tungsten-oxide where bacterial inactivation was shown to be attributed to reactive chlorine species with negligible contribution from ${ }^{\bullet} \mathrm{OH}$ or other reactive oxygen species 
at current densities similar to those examined in our study. ${ }^{1325 / 41}$ The contribution of adsorption to the electrode surfaces was also minimal in the AOS reactor, as demonstrated by the absence of significant bacterial inactivation in the absence of iodine and/or electrical potential. The absence of attachment or adsorption to electrode surface has also been shown for electrochemical cells with mixed metal anodes. $\frac{13}{}$

To determine which electrochemical chamber, anodic or cathodic, is responsible for the bacterial inactivation exhibited by the AOS, an experiment was designed whereby a horizontally orientated AOS reactor was run continuously for 1 hour with outgoing ports on each chamber. RO water seeded with $\sim 10^{8} \mathrm{CFU} / \mathrm{mL}$ E. coli was passed through the reactor. Within 15 minutes, E. coli counts decreased below the quantification limit, approximately a $6 \log _{10}$ reduction (Figure 3 ). No bacteria were detected in the effluent collected from the anodic chamber. This is in contrast with the effluent collected from the cathodic chamber where the bacterial concentration was equal to that of the influent feed water and did not change over the course of the experiment (Figure 3). These results indicate that inactivation of bacteria in the presence of potassium iodide and electrical potential occurs within the anodic chamber. Anodic generation of disinfecting species, predominately reactive chlorine species, has been shown in electrochemical cells composed of $\mathrm{BDD}$, graphite felt $/ \mathrm{PbO}_{2}$, antimony-doped tin-tungsten-oxide, and $\mathrm{BiO}_{x} / \mathrm{TiO}_{2}$ electrodes. ${ }^{13125141 / 42}$ Furthermore, periodate $\left(\left[\mathrm{IO}_{4}\right]^{-}\right)$electrochemically generated at the surface of a graphite electrode has previously been shown to inactivate E. coli. ${ }^{19}$

The hydraulic retention time and current density required to achieve a $6 \log _{10}$ reduction using the AOS technology was 5 minutes and $0.6 \mathrm{~mA} / \mathrm{cm}^{2}$. This number is similar to published values for $E$. coli inactivation from other studies using electrochemical cells. In general, as current density increases, reaction time decreases until a threshold value for current density is reached ${ }^{[1113143}$ Ghasemian et al. showed that a cell composed of a mixed metal electrode required 5 minutes for a $7.4 \log _{10}$ reduction in $E$. coli at a current density of $2 \mathrm{~mA} / \mathrm{cm}^{2}$. Their system's threshold was reached at $6 \mathrm{~mA} / \mathrm{cm}^{2}$ where a $7.4 \log _{10}$ reduction was achieved in 1 minute. Similarly, for a BDD-based system, time to achieve a $5 \log _{10}$ reduction decreased as current density increased from $7.5 \mathrm{~mA} / \mathrm{cm}^{2}$ to $120 \mathrm{~mA} / \mathrm{cm}^{2}{ }^{411} \mathrm{In}$ comparison, the AOS required an order of magnitude lower current density at a comparable retention time to achieve similar bacterial kill kinetics in this study. This could be a result of factors including: A) greater titers of active iodine oxidants generated within 
the AOS' anodic chamber compared to other electrochemical systems, and/or B) the generation of more active iodine oxidants that increase the disinfection potential of the AOS compared to similar electrochemical systems. Operando X-ray absorption studies described below reveal the presence of highly oxidized iodine species, which is consistent with the latter hypothesis.

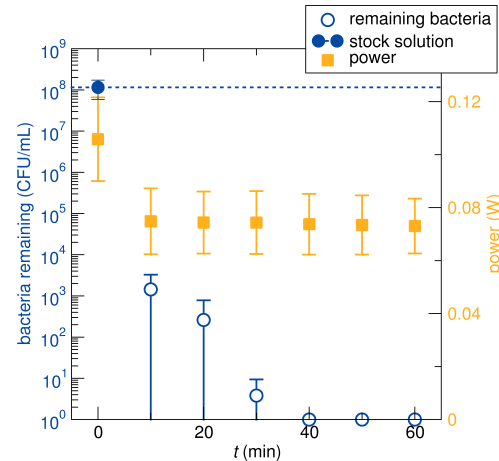

(a)

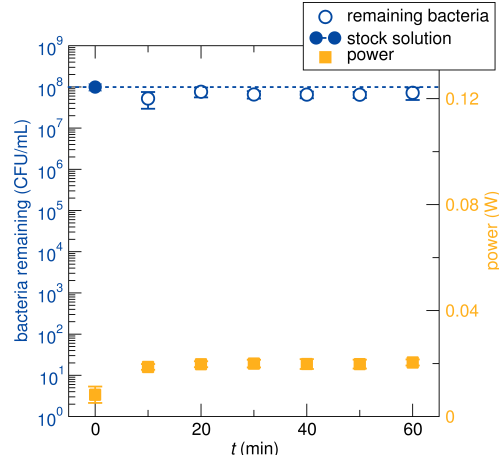

(b)

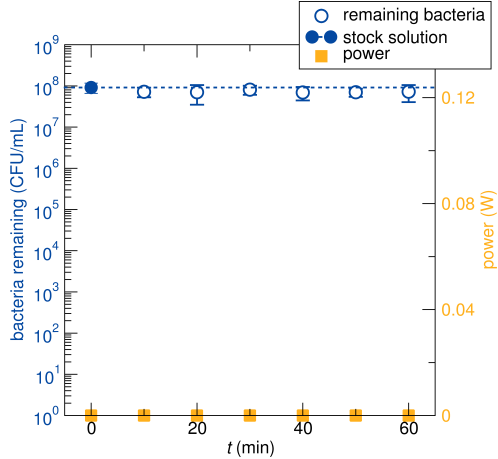

(c)

FIG. 2: RO water seeded with $\sim 10^{8} \mathrm{CFU} / \mathrm{mL}$ E. coli was passed through a 2", 6-chamber AOS reactor at $80 \mathrm{~mL} / \mathrm{min}$. (a) $6 \mathrm{~V}, 10 \mathrm{ppm} \mathrm{KI}$; (b) 6V, 0 ppm KI; (c) 0V, 0 ppm KI. Stock

E. coli in $\log \mathrm{CFU} / \mathrm{mL}$ (circles), $\log \mathrm{CFU} / \mathrm{mL} \sim 10^{8} \mathrm{CFU} / \mathrm{mL}$ E. coli remaining after treatment (squares), and power consumption of the reactor (triangles). Results are expressed as the mean; error bars represent the standard deviation from triplicate experiments. The AOS reactor is effective at inactivating $E$. coli only in the presence of all three components: expanded graphite, KI in solution, and an applied electric potential.

\section{B. Operando mapping of iodine distribution using I K edge X-ray fluorescence}

To determine the location of the iodine species believed to be responsible for the exceptional killing efficiency observed in the biological studies shown above, X-ray fluorescence (XRF) mapping at the iodine $\mathrm{K}$ edge $(\sim 33 \mathrm{keV})$ was performed on a standard 6-chamber BioLargo AOS reactor during operation (Figure 4). The fluorescence intensity is proportional to the number of iodine atoms being irradiated, and the high energy X-rays characteristic of the I K edge penetrate the reactor and allow a true bulk measurement of the spatial distribution of iodine species present - the absorption length, or the distance after which the irradiating beam intensity has decreased to $1 / e I_{0} \sim 0.37 I_{0}$, at $33 \mathrm{keV}$ in water 


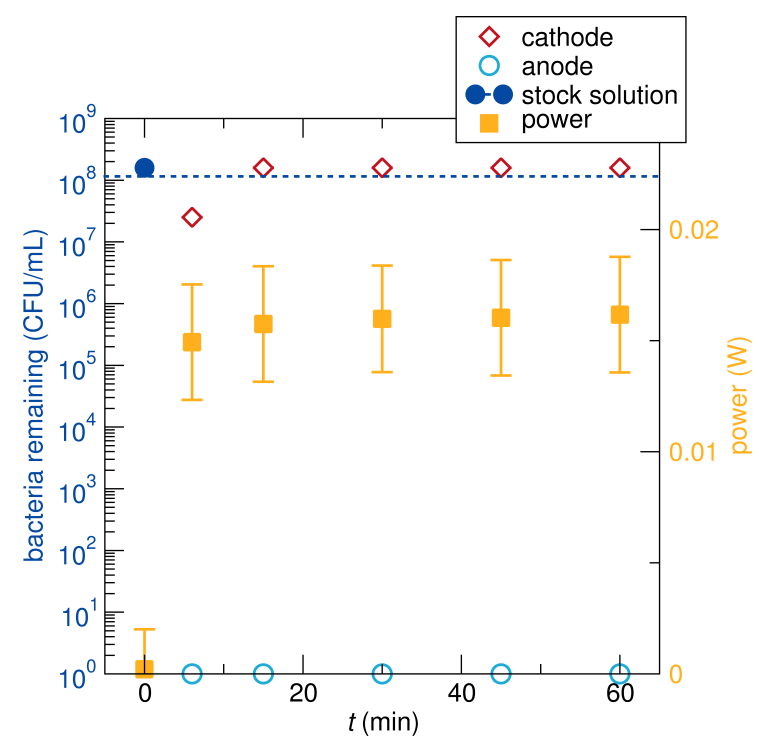

FIG. 3: RO water seeded with $\sim 10^{8} \mathrm{CFU} / \mathrm{mL}$ E. coli was passed through a horizontal 1", 2-chamber AOS reactor at $20 \mathrm{~mL} / \mathrm{min}, 50 \mathrm{ppm} \mathrm{KI}$, and $12 \mathrm{~V}$. Stock E. coli in log CFU/mL (filled circles), $\log \mathrm{CFU} / \mathrm{mL}$ E. coli remaining cathodic chamber (hollow diamond), $\log \mathrm{CFU} / \mathrm{mL}$ E. coli remaining anodic chamber (hollow circle), and power consumption of the reactor (square). Measurements from the aliquots taken from the cathodic chamber show no decrease in E. coli counts, whereas measurements from aliquots taken from the anodic chamber demonstrate inactivation of E. coli.

is $\lambda=3 \mathrm{~cm}$.

XRF mapping using a motorized stage was performed to determine the spatial distribution of iodine within the reactor during operation. (Absorption spectra were collected subsequently at regions of interest during each operation mode to determine the nature of the iodine species present, described later.) A 6-chamber BioLargo AOS reactor filled with 1000 ppm KI was mapped using XRF while in 3 different conditions: pristine $(0 \mathrm{~mL} / \mathrm{min}$ $1000 \mathrm{ppm} \mathrm{KI}, 0 \mathrm{~V})$, flow mode ( $4 \mathrm{~mL} / \mathrm{min} 1000 \mathrm{ppm} \mathrm{KI}, 12 \mathrm{~V})$, and batch mode $(0 \mathrm{~mL} / \mathrm{min}$ 1000 ppm KI, 12 V).

The 6-chamber reactor used is $14.5 \mathrm{~cm}$ high and $3.0 \mathrm{~cm}$ in diameter, and when fully packed, has a void fraction of $51 \%$ and thus a column volume corresponds to $\sim 50 \mathrm{~mL}$. To flush the reactor after operation, 30 equivalent column volumes of deionized water are flushed through the reactor at a rate of 1 column volume per minute. A separate experiment using the same flow rate, and a similarly packed reactor filled with a solu- 
tion containing strongly coloured organic dye, determined that flushing with 30 column volumes of deionized water leads to a $10^{3}$ reduction in dye concentration. The organic dye has similar affinity to the expanded graphite as iodine, so flushing with a large excess of deionized water ensures any remaining species in solution initially in the reactor are nearly removed (i.e. are diluted by a factor of 1000).

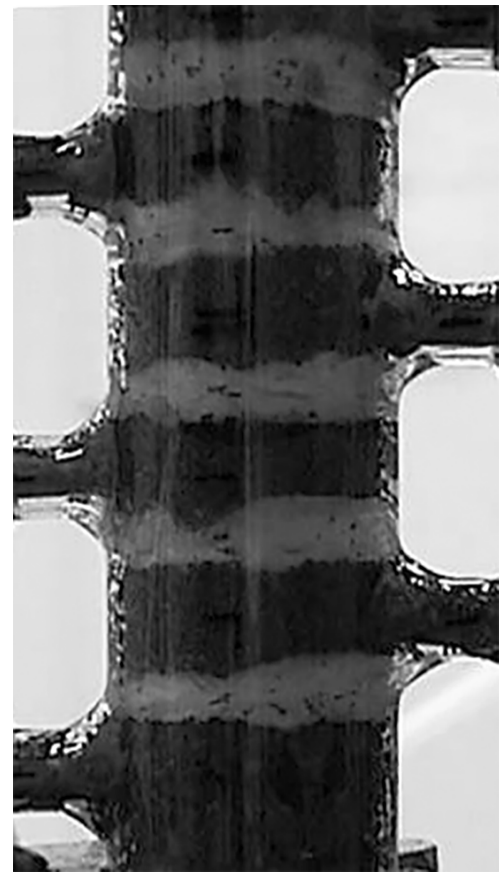

(a)

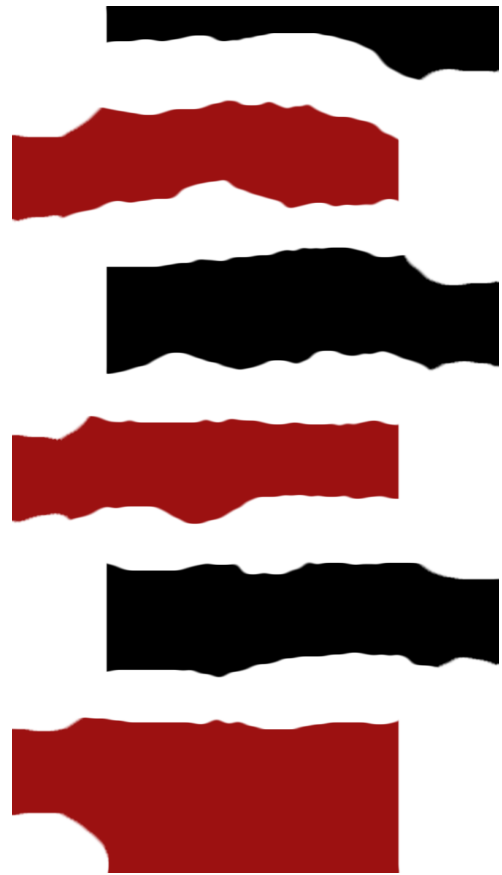

(b)

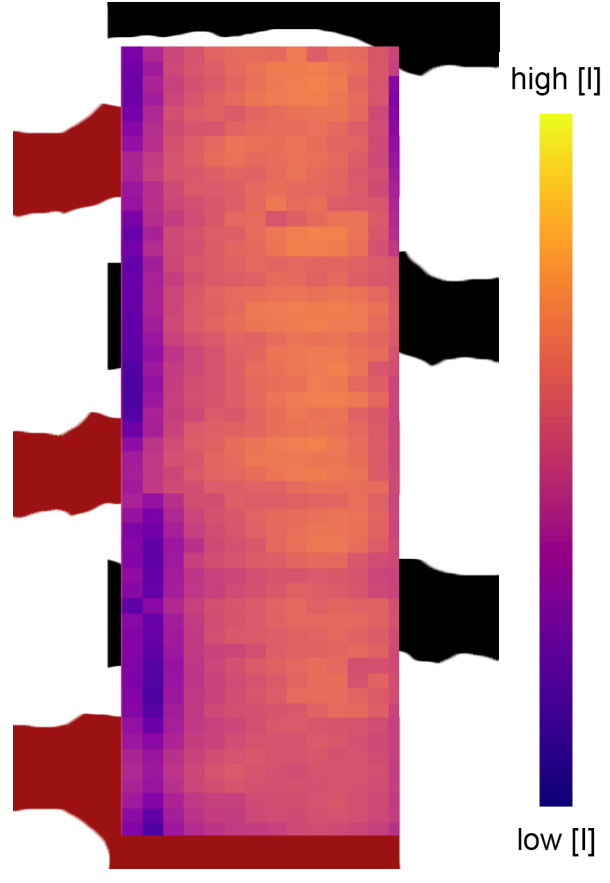

(c)

FIG. 4: (a) Photo of the 6-chamber reactor, as mounted at the beamline. (b) Schematic of the same 6-chamber reactor; anodic chambers (red) are connected at the left of the apparatus, cathodic chambers (black) are connected at the right. (c) X-ray fluorescence map of I species in a pristine reactor are overlaid on the reactor schematic, showing I is homogeneous before operation.

In the pristine reactor filled with an aqueous solution of $1000 \mathrm{ppm} \mathrm{KI}(0 \mathrm{~mL} / \mathrm{min}$ 1000 ppm KI, 0V applied across the reactor), XRF maps show uniform intensity, indicating I is evenly distributed throughout the reactor (Figure $4 \mathrm{C}$ ). The reactor was then operated in flow mode with the same solution $(4 \mathrm{~mL} / \mathrm{min} 1000 \mathrm{ppm} \mathrm{KI}, 12 \mathrm{~V})$, and XRF maps reveal increased relative and absolute fluorescence intensity at the anodic regions (Figure 5a). In addition to indicating I is heterogeneously distributed in the reactor during operating conditions, the significantly higher absolute intensity suggests I preferentially 
accumulates in the anodic chambers. Following the flow studies, the reactor was flushed with excess deionized water to remove any excess I species.

Finally, the reactor was flushed with 1000 ppm KI solution and then operated without flow in batch mode $(0 \mathrm{~mL} / \mathrm{min} 1000 \mathrm{ppm} \mathrm{KI}, 12 \mathrm{~V})$, and the corresponding XRF map displays higher relative intensity at anodic regions despite having no flow (Figure 5b). This heterogeneity does not become expressed until an electric potential is applied across the reactor, suggesting enrichment of the anodic regions is likely aided by electromigration. Activated carbon materials are known to physically adsorb iodine, though given the reactor conditions it is likely that electrochemical reaction and subsequent modification of the expanded graphite and/or chemical incorporation and absorption of iodine species may occur to some extent. Nevertheless, the potential presence of these species alone does not lead to inactivation of $E$. coli if water is subsequently passed through the reactor; the presence of all components mentioned earlier is still necessary: expanded graphite, KI, and an applied electric potential.

\section{Operando speciation of iodine using I K edge X-ray absorption spectroscopy}

To determine the nature of the active species responsible for the exceptional killing efficiency observed in the biological studies shown earlier, iodine speciation using X-ray absorption spectroscopy (XAS) was performed on all chambers during operation of the reactor. As described earlier, the high energy of the incident X-rays at the I K edge are highly penetrating, and provide a bulk measurement of the iodine species present in the reactor.

Importantly, we distinguish here the oxidation state, which we treat to be directly related to the ground state charge density and the degree of electron deficiency, from the formal charge, which is the charge assigned to an atom under the assumption of complete charge transfer in a compound with purely ionic interactions. Iodine is large and

polarizable, and the strong bonding within polyoxo anionic species discussed here lead to bonding very far from this ionic limit. Formal charges are thus used here to compare the relative oxidation state. For example, e.g., iodine in $\left[\mathrm{IO}_{3}\right]^{-}$is formally $\mathrm{I}^{5+}$, whereas iodine in $\left[\mathrm{IO}_{4}\right]^{-}$is formally $\mathrm{I}^{7+}$. This merely implies iodine in $\left[\mathrm{IO}_{4}\right]^{-}$is more electron deficient than $\left[\mathrm{IO}_{3}\right]^{-}$, and not that iodine in $\left[\mathrm{IO}_{4}\right]^{-}$has no electrons. 


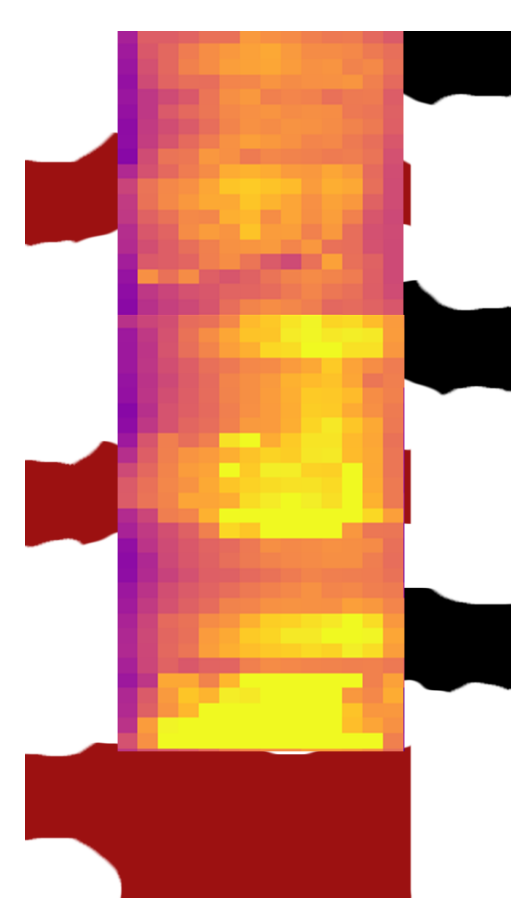

(a)

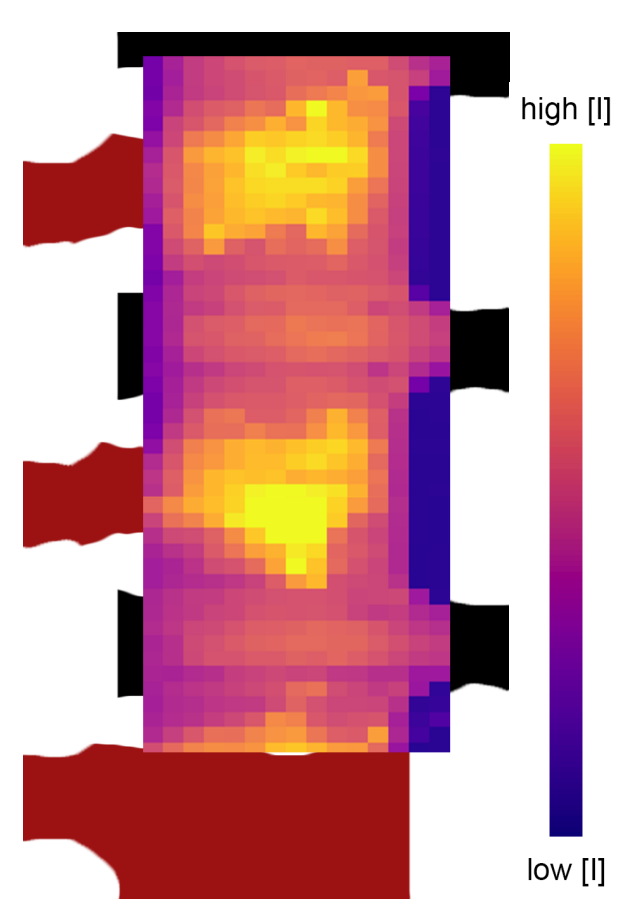

(b)

FIG. 5: X-ray fluorescence maps of total I species overlaid on the 6-chamber reactor schematic. Yellow corresponds to regions of high I concentration (see colour bar). (a) The XRF map of a the operational reactor in flow mode ( $4 \mathrm{~mL} / \mathrm{min} 1000 \mathrm{ppm} \mathrm{KI}, 12 \mathrm{~V}$ ) exhibits increased absolute and relative fluorescence intensity at anodic regions, indicating I preferentially accumulates in anodic chambers. (b) The XRF map of the reactor in batch mode $(0 \mathrm{~mL} / \mathrm{min} 1000 \mathrm{ppm} \mathrm{KI}, 12 \mathrm{~V})$ displays higher relative intensity at anodic regions despite having no flow, suggesting electromigration likely takes place to enrich I concentration in anodic chambers.

The I K edge X-ray absorption near edge structure (XANES) is characteristic of the iodine oxidation state, which allows the determination of the iodine species in the reactor. ${ }^{44} \sqrt[46]{ }$ Specifically, as the oxidation state of iodine increases - the ground state electron density at iodine decreases and iodine becomes more electron deficient - the onset energy and the intensity of the primary absorption feature increase. With increasing oxidation state, the remaining electrons on iodine are lower in energy and thus more difficult to promote to unoccupied states, increasing the observed X-ray absorption energy observed. Similarly, with increasing oxidation state there are more unoccupied iodine electronic states, which increases the transition probability and thus the intensity of the 
X-ray absorption feature.

When there are multiple species present, the resulting spectrum is a linear combination of the two component spectra, which allows semi-quantitative determination of iodine species present. Although the relative concentration of species with respect to each other can be determined, to aid identification, the lineshape and peak intensity in the spectra reported here are normalized to a single absorbing atom and are thus independent of the absolute concentration - lower absolute concentration will merely lead to spectra with more noise.

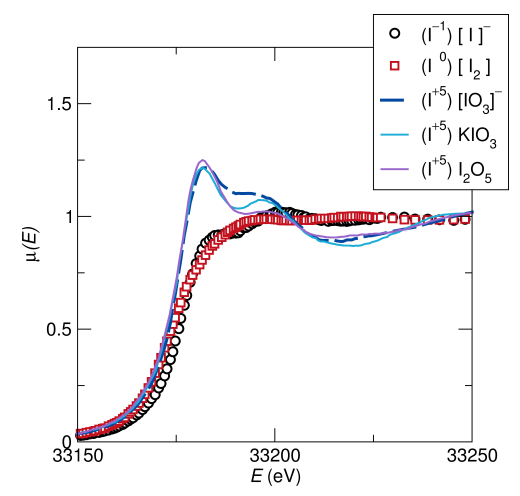

(a)

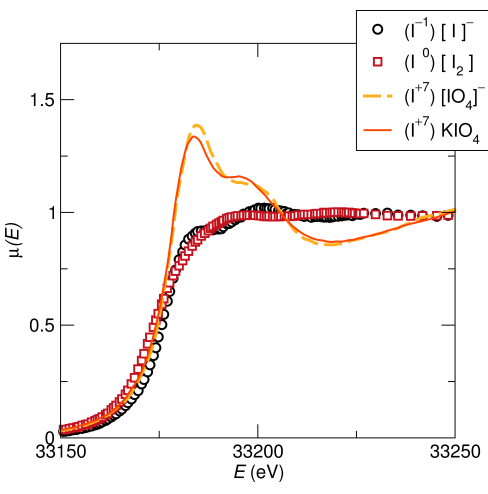

(b)

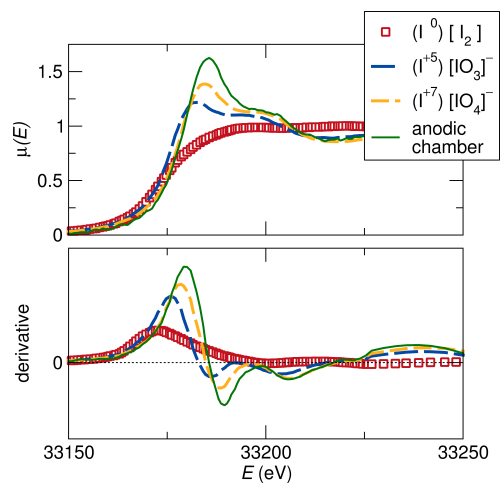

(c)

FIG. 6: I K edge XANES from (a) $\mathrm{I}^{5+}$ and (b) $\mathrm{I}^{7+}$ reference compounds in the solid state (solid lines) and solution (dashed lines). The absorption onset energy and peak intensity depend primarily on the oxidation state of iodine. The spectral features of the solution species are slightly broader in energy than their solid analogues, as the chemical environment around iodine is not as uniform in solution as in a crystalline powder. Compared to iodine in lower oxidation states (e.g., $\mathrm{I}_{2}$ ), the XANES of iodine in higher oxidation states has a higher absorption energy, and a pronounced peak whose intensity increases with oxidation state. (c) I K edge XANES of the anodic chambers in the reactor has a higher absorption energy and peak intensity than any reference compound measured here or seen in the literature, suggesting the presence of an iodine species more oxidized than $\left[\mathrm{IO}_{4}\right]^{-}$.

Solid powder and $1000 \mathrm{ppm}$ solution standards of reference compounds were prepared to facilitate identification of iodine species and relative oxidation states (Figure 6); reference spectra shown here are consistent with previous reports. ${ }^{\sqrt[44]{46}}$ Solution species show 
similar spectral features (e.g., the absorption energy and peak intensity) to solid compounds with the same formal charge, as the absorption energy and peak intensity depend primarily on the oxidation state of iodine. Notably, the spectral features of the solution species are slightly broader in energy than their solid analogues, as the chemical environment around iodine is not as uniform in solution as in a crystalline powder, leading to a larger distribution of states in energy.

Oxidized iodine species are clearly distinct from iodine species with lower oxidation state. As described earlier, the increasing iodine oxidation state leads to an increased absorption energy, and, most notably and diagnostically, a large peak intensity at the absorption edge due to an increased probability of transition to a larger number of unoccupied electronic states. This peak intensity increases with oxidation state, as can be seen in the evolution from $\mathrm{I}^{5+}$ species to $\mathrm{I}^{7+}$ species (Figure 6).

XANES measurements performed on anodic chambers of the operating reactor consistently produce spectra with increased absorption energy and peak intensity compared to $\left[\mathrm{IO}_{4}\right]^{-}$(Figure 6), which has the highest formal charge of reference species measured here. Although the identity of the species cannot be determined, the increased absorption energy and peak intensity unambiguously indicate this new species being formed in the reactor has iodine which more electron deficient than $\left[\mathrm{IO}_{4}\right]^{-}$.

We suggest the in situ generation of this highly oxidized species may be responsible for the exceptional killing efficiency observed in the biological studies reported above. As discussed in the experiments reported in following sections, this killing efficiency can not be attributed to other possible biological stressors generated by the reactor, such as changes in $\mathrm{pH}$, electrical potential, and/or hydroxyl radicals. These processes are known to occur in any electrochemical oxidative water treatment processes, though the exceptional killing activity observed here is only observed in the presence of iodine species.

In contrast to the anodic chambers, X-ray absorption spectra collected from the cathodic chambers are consistent with $\mathrm{I}^{-}$(Figure 7), suggesting any active species generated in the anodic chamber are reduced in the subsequent cathodic chamber. XANES measurements performed on the cathodic chambers have much lower signal intensity than anodic chambers due to the preferential accumulation of I species in the anodic chambers observed by XRF mapping discussed earlier; the spectrum from the cathode shown in Figure 7 required a factor of 4 increase in collection time, but nevertheless there is no evidence for 
the presence of highly oxidized species in the cathodic chambers, nor do we see evidence of any species other than $\mathrm{I}^{-}$.

Measurements of the glass wool spacers did not have sufficient signal to determine the presence of any iodine species. Moreover, spectra collected from the effluent are consistent with spectra consistent with $\mathrm{I}^{-}$(Figure 7), suggesting that to within the limits of the technique, any species generated are no longer present in the reactor effluent.

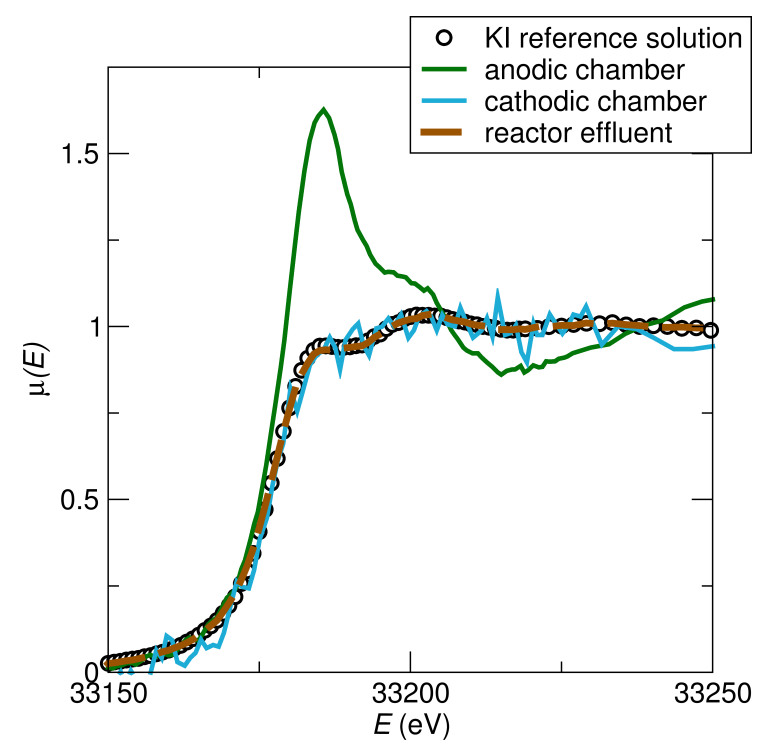

FIG. 7: I K edge X-ray absorption spectra collected from the effluent (dashed) are consistent with spectra consistent with $\mathrm{I}^{-}$, suggesting that to within the limits of the technique, any highly oxidized species generated in the reactor anodic chambers are destroyed before exiting the reactor in the effluent. Spectra from the cathodic chamber have similar lineshape, and are also consistent with the presence of only $\mathrm{I}^{-}$. This suggests any active species generated in the anodic chamber are subsequently reduced in the cathodic chamber that follows downstream. The signal from the cathodic chamber is noisier due to a lower absolute concentration of I, as seen in XRF maps.

\section{Ex situ cyclic voltammetry of iodine species at an EG electrode}

Operando XANES measurements of the AOS reactor reveal the presence of a highly oxidized iodine species when the reactor is operated in the presence of a $1000 \mathrm{ppm}$ KI solution. 1000 ppm KI was chosen because it is the lowest concentration at which sufficient 
signal can be obtained from XANES measurements with relevant data collection times, while still remaining in a possible operational window of the reactor. Nevertheless, the exceptional killing efficiency of the AOS reactor can be demonstrated at concentrations as low as 5 ppm KI, and anticipated treatment applications are expected to operate at concentrations $<25 \mathrm{ppm} \mathrm{KI}$. Accordingly, ex situ and operando electrochemical methods were performed to investigate the redox species being generated at lower iodine concentrations.

In order to determine the electrode potentials required to drive the desired reactions inside an AOS reactor, and in order to characterize the electrochemical properties of the EG used in AOS reactors, cyclic voltammetry (CV) was carried out. In the absence of iodide, no redox reactions were evident at $\mathrm{pH} 7.6$ within a potential window of $0.0 \mathrm{~V}$ to $1.0 \mathrm{~V}$ versus $\mathrm{Ag} / \mathrm{AgCl}$ (Figure 8). However, in the presence of iodide, three redox couples are observed at half-cell potentials of $E_{1 / 2}=0.37 \mathrm{~V}, 0.51 \mathrm{~V}$ and $0.68 \mathrm{~V}$, as well as an anodic peak near $0.9 \mathrm{~V}$ versus the $\mathrm{Ag} / \mathrm{AgCl}$ reference electrode. Based on the standard reduction potentials of iodide oxidation reactions (Equations (1) to (3)), 47 , t51 the redox couples at $0.37 \mathrm{~V}$ and $0.51 \mathrm{~V}$ are attributed to a two-step redox reaction shown in Equation (1) and Equation (2). The first peak at $0.37 \mathrm{~V}$ shows the oxidation of $\mathrm{I}^{-}$to $\mathrm{I}_{3}{ }^{-}$and the second peak at $0.51 \mathrm{~V}$ shows the oxidation of $\mathrm{I}_{3}{ }^{-}$to $\mathrm{I}_{2} \cdot{ }^{5253}$ (It is possible the two peaks may be associated with a combination of adsorption and electron transfer steps. ${ }^{48 / 49 \mid 53}$ However, coupled electrochemical reactions and adsorption processes can complicate the voltammetry, and more detailed studies beyond the scope of this work would be needed to confirm the reaction mechanism.) The redox couple observed at $0.68 \mathrm{~V}$ versus $\mathrm{Ag} / \mathrm{AgCl}$ is attributed to the $\mathrm{I}^{-} / \mathrm{IO}_{3}{ }^{-}$redox process (Equation $(3 \mathrm{p})$ ). Accounting for the effect of the $\mathrm{pH}$, the redox potential of this reaction is expected to be around $0.68 \mathrm{~V}$ versus $\mathrm{Ag} / \mathrm{AgCl}$ at a $\mathrm{pH}$ of 7.6. The anodic peak observed at $0.9 \mathrm{~V}$ versus $\mathrm{Ag} / \mathrm{AgCl}$ is attributed to oxidation of iodate to periodate (Equation (4)) accounting for the effect of $\mathrm{pH}$ on the redox potential. ${ }^{1954 \mid 55}$

$$
\begin{aligned}
3 \mathrm{I}^{-} & \rightleftharpoons \mathrm{I}_{3}^{-}+2 \mathrm{e}^{-} \\
2 \mathrm{I}_{3}^{-} & \rightleftharpoons 3 \mathrm{I}_{2}+2 \mathrm{e}^{-} \\
\mathrm{I}^{-}+3 \mathrm{H}_{2} \mathrm{O} & \rightleftharpoons \mathrm{IO}_{3}{ }^{-}+6 \mathrm{H}^{+}+6 \mathrm{e}^{-} \\
\mathrm{IO}_{3}{ }^{-}+2 \mathrm{OH}^{-} & \rightleftharpoons \mathrm{IO}_{4}^{-}+\mathrm{H}_{2} \mathrm{O}+2 \mathrm{e}^{-}
\end{aligned}
$$




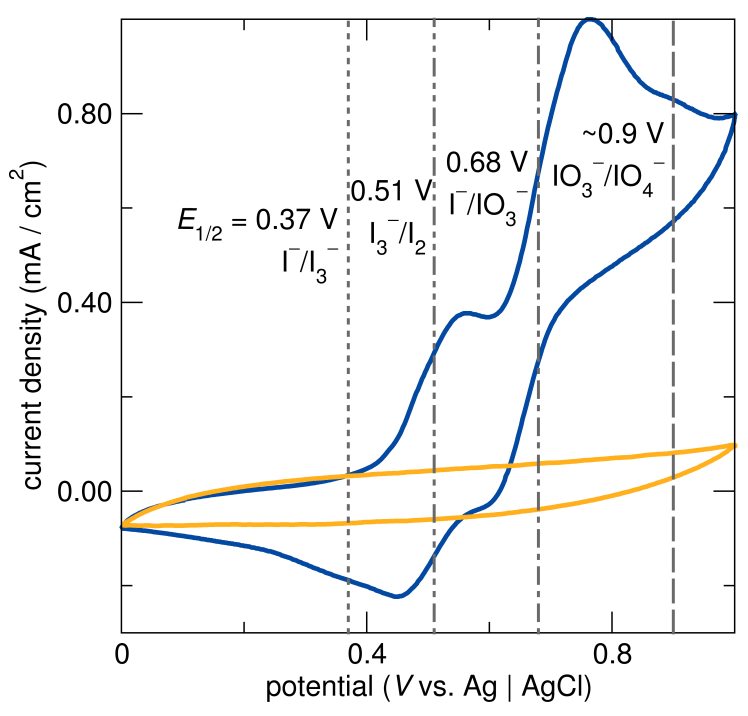

FIG. 8: Cyclic voltammogram obtained for an EG pellet electrode in $100 \mathrm{ppm}$ KI solution (0.6 mM KI, $0.1 \mathrm{M} \mathrm{Na}_{2} \mathrm{SO}_{4}, 0.1 \mathrm{M}$ phosphate buffer at $\mathrm{pH}$ 7.6) with a potential window of $0.0 \mathrm{~V}$ to $1.0 \mathrm{~V}$, and a scan rate of $0.01 \mathrm{~V} \mathrm{~s}^{-1}$. The yellow line shows the voltammogram obtained for the background solution in the absence of iodide. No anodic/cathodic peaks were observed in the background solution, suggesting that the background current was only associated with the capacitive charging and discharging the double layer at the electrode surface, and that all significant electrochemical activity is associated with the presence of KI. In the presence of KI, dashed lines highlight the three redox couples observed at half-cell potentials of $E_{1 / 2}=0.37 \mathrm{~V}, 0.51 \mathrm{~V}$ and $0.68 \mathrm{~V}$, as well as an anodic peak near $0.9 \mathrm{~V}$ versus the $\mathrm{Ag} / \mathrm{AgCl}$ counter electrode

\section{E. Operando potential distribution measurement of an AOS reactor}

The electrode potential, corresponding to the potential difference between the expanded graphite (EG) electrode and the solution, determines the electrochemical reactions occurring in the AOS reactor. Accordingly, a reactor was modified to measure the distribution of the electrical potential within the electrode chambers (Figure 1b), with the goal of probing the electrochemical reactions occurring at the electrodes during operation of the reactor.

The measured local potential in the electrode bed at different positions relative to the glass wool spacer in the AOS reactor is shown in Figure 9. In order to oxidize $\mathrm{I}^{-}$to $\mathrm{IO}_{3}{ }^{-}$, 


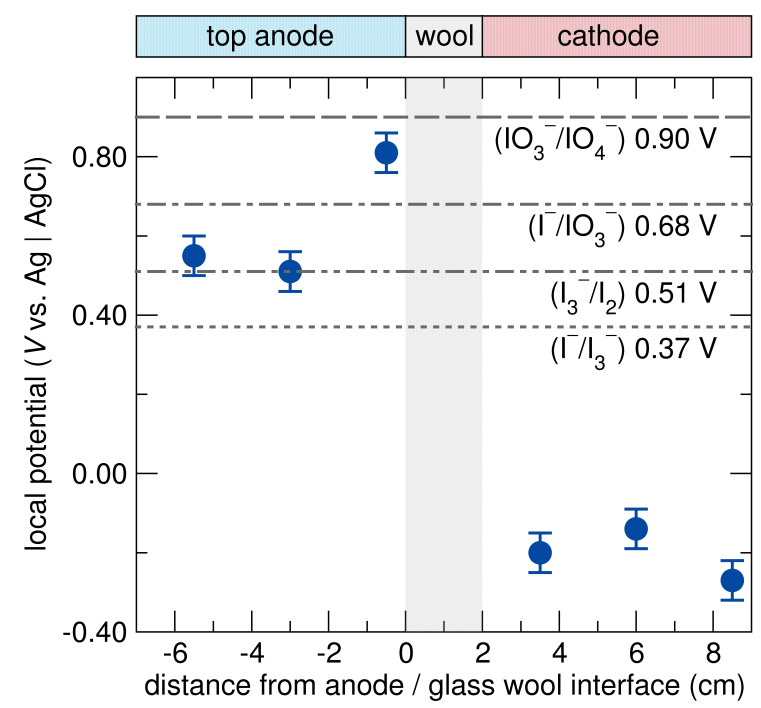

FIG. 9: Distribution of electrical potential in the anode and cathode chambers of the AOS reactor during current and solution flow. The applied cell voltage was $10 \mathrm{~V}$, and the current was $9.42 \mathrm{~mA}$. The solution flow rate was $100 \mathrm{~mL} / \mathrm{min}$, with a composition of $100 \mathrm{ppm} \mathrm{KI}$ and $0.4 \mathrm{wt} . \% \mathrm{Na}_{2} \mathrm{SO}_{4}\left(0.6 \mathrm{mM} \mathrm{KI}, 0.1 \mathrm{M} \mathrm{Na}_{2} \mathrm{SO}_{4}\right)$. The long dashed line corresponds to the $0.9 \mathrm{~V}$ potential required for redox reaction of $\mathrm{IO}_{3}{ }^{-}$to $\mathrm{IO}_{4}{ }^{-}$at $\mathrm{pH} 7.6$ (as determined by the cyclic voltammetry). The dot-dashed line corresponds to the $0.68 \mathrm{~V}$ potential required for redox reaction of $\mathrm{I}^{-}$to $\mathrm{IO}_{3}{ }^{-}$at $\mathrm{pH}$ 7.6, and the remaining dotted lines correspond to the $\mathrm{I}^{-} / \mathrm{I}_{3}{ }^{-}$and $\mathrm{I}_{3}{ }^{-} / \mathrm{I}_{2}$ redox reactions occurring at $0.37 \mathrm{~V}$ and $0.51 \mathrm{~V}$.

potentials more positive than $0.68 \mathrm{~V}$ versus $\mathrm{Ag} / \mathrm{AgCl}$ are required at $\mathrm{pH} 7.6$, while $\mathrm{IO}_{3}{ }^{-}$ can be reduced to $\mathrm{I}^{-}$at potentials less positive than $0.68 \mathrm{~V}$. Similarly, at potentials above $0.5 \mathrm{~V} \mathrm{I}^{-}$can be oxidized to $\mathrm{I}_{2}$ and below $0.37 \mathrm{~V}$ reduction to $\mathrm{I}^{-}$will occur. At potentials above $0.9 \mathrm{~V}, \mathrm{IO}_{3}{ }^{-}$can be oxidized to $\mathrm{IO}_{4}{ }^{-}$at $\mathrm{pH}$ 7.6.

In the cathode of the AOS reactor (position 4, 5 and 6), all local electrode potentials were less than the redox potential for the $\mathrm{I}^{-} / \mathrm{I}_{3}{ }^{-}, \mathrm{I}_{3}{ }^{-} / \mathrm{I}_{2}$ and $\mathrm{I}^{-} / \mathrm{IO}_{3}{ }^{-}$couples and also for the $\mathrm{IO}_{4}{ }^{-} / \mathrm{IO}_{3}{ }^{-}$redox processes, which indicates that at all positions in the cathode of the AOS it is expected that iodine in higher oxidation states will be reduced to iodide. In the anode, the electrode potentials at position 8 and 9 are not sufficient for iodate formation, but are just sufficient for iodine and triiodide formation. At position 7, close to surface of the anode facing the cathode, the electrode potential was measured to be $0.81 \mathrm{~V}$ versus $\mathrm{Ag} / \mathrm{AgCl}$, which is sufficient for formation of iodine, triiodide and also iodate at $\mathrm{pH}$ 7.6. 
However, the electrode potential increases rapidly towards the surface (where the anode meets the glass wool), due to ohmic losses in the solution as the current flows into the porous electrode. At this interface between the anode and the glass wool, the electrode potential should be significantly higher than $0.81 \mathrm{~V}$, leading to formation of periodate or species with higher oxidation states along with iodate, iodine and triiodide.

Further, The $\mathrm{pH}$ of the solution in the top glass wool between the to the cathode and the top anode electrode was found to be $\mathrm{pH} \sim 11.5$. This high $\mathrm{pH}$ decreases the redox potential for $\mathrm{I}^{-} / \mathrm{IO}_{3}{ }^{-}$and $\mathrm{IO}_{4}{ }^{-} / \mathrm{IO}_{3}{ }^{-}$redox processes, facilitating the formation of the iodate and periodate at the anode. Similarly, acidic conditions in solution flowing in the bottom glass wool entering the cathode (where the $\mathrm{pH}$ was found to be $\mathrm{pH} 3.5$ ) increases the redox potential for the $\mathrm{pH}$-dependent redox processes, increasing the overpotential for the reduction of the species at the cathode.

The electrochemical studies are consistent with results from operando XANES measurements and the microbiological studies performed here. Namely, the high $\mathrm{pH}$ and high voltages observed in the anodic chamber near the glass wool interface favour the formation of highly oxidized iodine species, which we observe using XANES, and which are seen to rapidly inactivate $E$. coli at low current densities and short contact times. Further, electrochemical studies also confirm that $\mathrm{pH}$ and voltage in the cathodic chamber favours the reduction of oxidized species to iodide, which was the sole iodine product observed by XANES in the effluent.

While our studies demonstrate favourable conditions in the cathodic chambers for reduction of iodine species to iodide (along with XANES measurements that detect only iodide in the reactor effluent), the potential formation and/or accumulation of trace byproducts that are below the detection limit of the techniques used in this work cannot be ruled out. The production of oxidation refractory intermediates including disinfection by-products is a limitation of many eAOPs, though a previous study screening for routine disinfection by-products has shown that effluent from the BioLargo AOS contains lower levels of known disinfection by-products than municipal tap water. Further work is ongoing to define any disinfection by-products present in AOS effluent, and to inform future mitigation strategies for the technology.

As discussed at the outset of this paper, eAOPs are a promising class of treatment technologies to provide effective treatment of wastewater for reuse, but have several down- 
sides, principal among which is high electricity consumption. This study demonstrates that the eAOP examined herein, the AOS, is capable of achieving high rates of bacterial inactivation while using a lower current density and a shorter contact time than conventional eAOPs. This suggests that this eAOP may either itself serve as the basis for an effective and scalable wastewater treatment solution, or may be a useful component of a treatment train aimed at providing treatment for municipal or industrial wastewater. Furthermore, the characterization of the iodine-based eAOP described herein provides a basis for future work to improve other eAOPs for use in water treatment. While traditionally, eAOPs have suffered from poor energy consumption and therefore cost-efficiency, the significant improvement in current density required for bacterial inactivation observed with the AOS suggests there is potential for refinement of eAOP reactors to maximize contaminant removal kinetics relative to input costs, stemming from the exploitation of previously unused halide species of higher oxidation potential.

\section{CONCLUSIONS}

We present a simple electrochemical advanced oxidation process (eAOP) reactor consisting of expanded graphite, $\mathrm{KI}$ in solution, and an applied electric potential. The reactor demonstrates an exceptionally high rate of inactivation of $E$. coli $\left(6 \log _{10}\right.$ reduction in viable cells) at low current density $\left(0.6 \mathrm{~mA} / \mathrm{cm}^{2}\right)$, short contact times, and low iodine concentrations. As discussed above, this killing efficiency can not be attributed to other possible biological stressors generated by the reactor, such as changes in $\mathrm{pH}$, electrical potential, and/or hydroxyl radicals. These processes are known to occur in any electrochemical oxidative water treatment processes, though the exceptional killing activity observed here is only observed in the additional presence of iodine species, reported in this work.

The killing efficiency of this eAOP reactor observed in the biological studies far exceeds that expected from either KI or advanced oxidation systems alone, which may be associated with the in situ generation of highly oxidized iodine species observed in the anodic chamber using operando X-ray absorption spectroscopy and electrochemical measurements conducted separately. The exact nature of the most highly oxidized species

observed remains unknown, though future studies involving mass spectrometry and other analytical techniques may be helpful to elucidate the identity. 


\section{ACKNOWLEDGMENTS}

Part of the research described in this paper was performed at the Canadian Light Source, a national research facility of the University of Saskatchewan, which is supported by the Canada Foundation for Innovation (CFI), the Natural Sciences and Engineering Research Council (NSERC), the National Research Council (NRC), the Canadian Institutes of Health Research (CIHR), the Government of Saskatchewan, and the University of Saskatchewan. We thank the Natural Sciences and Engineering Research Council of Canada for support through NSERC Engage and Engage PLUS grants [KM: EGP-499182-16, EGP2-507089-17; ER: EGP-503902-16, EGP2-523101-18].

[Declaration of interest statement.] NB, RA, KM, ZF, and ER received research support from BioLargo Inc., who have a patent on the reactor (US patent 10,654,731 B2). AM, $\mathrm{AE}, \mathrm{SH}, \mathrm{JB}, \mathrm{PP}, \mathrm{CZ}, \mathrm{LPF}, \mathrm{CL}, \mathrm{RS}$, and $\mathrm{KC}$ are or were employed by BioLargo Inc. KRC is the Chief Science Officer at BioLargo Inc. and RS is the President and Chief Executive Officer of BioLargo Water Inc. MWG received financial compensation as a consultant for BioLargo Inc., and is a shareholder of BioLargo Inc. NC and PB have no competing interests.

\section{CONTRIBUTIONS}

AM designed the multi-chamber AOS reactor, contributed to the planning and execution of AOS work, synchotron experiments, and editing of the manuscript.

$\mathrm{AE}$ contributed to the design and execution of synchrotron experiments and disinfection experiments, and co-wrote the manuscript with MWG.

$\mathrm{SH}$ designed disinfection experiments and microbiological assays, and contributed to the design and execution of synchrotron experiments.

JB contributed to synchrotron experiments, data analysis, and writing and editing the manuscript.

PP and CZ contributed to disinfection experiments, synchrotron experiments, and data analysis.

CG contributed to disinfection experiments and data analysis of synchrotron experiments.

CL contributed to data analysis of synchrotron experiments. 
LPF designed and performed microbiological assays, analyzed microbiology results, and contributed to writing and editing of the manuscript.

RS created the initial design for the flow through AOS, was involved in design and execution of all AOS experiments, and contributed to synchrotron experiments and editing the manuscript.

KRC is the CSO for BioLargo and was the initial concept inventor and patent holder for the AOS, and was involved in all planning and long term research for the AOS.

All authors affiliated with BioLargo Water Inc. contributed to overall experimental analysis related to BioLargo AOS research.

NC and PERB contributed to synchrotron experiments.

NB contributed to synchrotron experiments, microbiological experiments, and editing the manuscript.

RA contributed to synchrotron experiments.

KM supervised NB, contributed to synchrotron experiments, and contributed to writing and editing the manuscript.

ZF designed and performed ex-situ voltammetry and operando potential distribution measurements, analyzed electrochemical data, and contributed to writing and editing the manuscript.

ER designed the setup for operando potential distribution measurements, supervised ZF for all electrochemical experiments and interpretation of the electrochemical data, and contributed to writing and editing the manuscript.

MWG conceived and contributed to the design of synchrotron experiments, supervised synchrotron experiments, wrote the first draft of the manuscript, and co-wrote the manuscript with AE.

\section{REFERENCES}

\section{REFERENCES}

${ }^{1}$ F. C. Moreira, R. A. Boaventura, E. Brillas, and V. J. Vilar, "Electrochemical advanced oxidation processes: A review on their application to synthetic and real wastewaters," Appl. Catal. B Environ. 202, 217-261 (2017). 
${ }^{2}$ D. B. Miklos, C. Remy, M. Jekel, K. G. Linden, J. E. Drewes, and U. Hübner, "Evaluation of advanced oxidation processes for water and wastewater treatment - A critical review," Water Res. 139, 118-131 (2018).

${ }^{3}$ P. Cañizares, R. Paz, C. Sáez, and M. A. Rodrigo, "Costs of the electrochemical oxidation of wastewaters: A comparison with ozonation and Fenton oxidation processes," J. Environ. Manage. 90, 410-420 (2009).

${ }^{4}$ O. Ganzenko, D. Huguenot, E. D. van Hullebusch, G. Esposito, and M. A. Oturan, "Electrochemical advanced oxidation and biological processes for wastewater treatment: A review of the combined approaches," Environ. Sci. Pollut. Res. 21, 8493-8524 (2014).

${ }^{5}$ S. O. Ganiyu, E. Vieira dos Santos, E. C. Tossi de Araújo Costa, and C. A. MartínezHuitle, "Electrochemical advanced oxidation processes (EAOPs) as alternative treatment techniques for carwash wastewater reclamation," Chemosphere 211, 998-1006 (2018). ${ }^{6}$ L. Feng, E. D. van Hullebusch, M. A. Rodrigo, G. Esposito, and M. A. Oturan, "Removal of residual anti-inflammatory and analgesic pharmaceuticals from aqueous systems by electrochemical advanced oxidation processes. A review," Chem. Eng. J. 228, 944-964 (2013).

${ }^{7}$ C. A. Martínez-Huitle and S. Ferro, "Electrochemical oxidation of organic pollutants for the wastewater treatment: Direct and indirect processes," Chem. Soc. Rev. 35, 1324 1340 (2006).

${ }^{8}$ P. Drogui, S. Elmaleh, M. Rumeau, C. Bernard, and A. Rambaud, "Hydrogen peroxide production by water electrolysis: Application to disinfection," J. Appl. Electrochem. 31, 877-882 (2001).

${ }^{9} \mathrm{~J}$. Jeong, C. Kim, and J. Yoon, "The effect of electrode material on the generation of oxidants and microbial inactivation in the electrochemical disinfection processes," Water Res. 43, 895-901 (2009).

${ }^{10}$ L. H. Tran, P. Drogui, G. Mercier, and J. F. Blais, "Electrochemical degradation of polycyclic aromatic hydrocarbons in creosote solution using ruthenium oxide on titanium expanded mesh anode," J. Hazard. Mater. 164, 1118-1129 (2009).

${ }^{11}$ E. Lacasa, E. Tsolaki, Z. Sbokou, M. A. Rodrigo, D. Mantzavinos, and E. Diamadopoulos, "Electrochemical disinfection of simulated ballast water on conductive diamond electrodes," Chem. Eng. J. 223, 516-523 (2013).

${ }^{12}$ R. Daghrir, P. Drogui, J. Tshibangu, N. Delegan, and M. A. El Khakani, "Electrochemi- 
cal treatment of domestic wastewater using boron-doped diamond and nanostructured amorphous carbon electrodes," Environ. Sci. Pollut. Res. 21, 6578-6589 (2014).

${ }^{13}$ S. Ghasemian, B. Asadishad, S. Omanovic, and N. Tufenkji, "Electrochemical disinfection of bacteria-laden water using antimony-doped tin-tungsten-oxide electrodes,"Water Res. 126, 299-307 (2017).

${ }^{14}$ S. O. Ganiyu, M. Zhou, and C. A. Martínez-Huitle, "Heterogeneous electro-Fenton and photoelectro-Fenton processes: A critical review of fundamental principles and application for water/wastewater treatment," Appl. Catal. B Environ. 235, 103-129 (2018).

${ }^{15}$ O. Ganzenko, C. Trellu, S. Papirio, N. Oturan, D. Huguenot, E. D. van Hullebusch, G. Esposito, and M. A. Oturan, "Bioelectro-Fenton: evaluation of a combined biological—advanced oxidation treatment for pharmaceutical wastewater," Environ. Sci. Pollut. Res. 25, 20283-20292 (2018).

${ }^{16} \mathrm{M}$. Mascia, A. Vacca, and S. Palmas, "Fixed bed reactors with three dimensional electrodes for electrochemical treatment of waters for disinfection," Chem. Eng. J. (2012), 10.1016/j.cej.2012.09.091.

${ }^{17}$ D. Ghernaout and B. Ghernaout, "From chemical disinfection to electrodisinfection: The obligatory itinerary?" Desalin. Water Treat. 16, 156-175 (2010).

${ }^{18}$ D. Ghernaout, A. Badis, A. Kellil, and B. Ghernaout, "Application of electrocoagulation in Escherichia coli culture and two surface waters," Desalin. 219, 118-125 (2008).

${ }^{19}$ M. Okochi, H. Yokokawa, T. K. Lim, T. Taguchi, H. Takahashi, H. Yokouchi, T. Kaiho, A. Sakuma, and T. Matsunaga, "Disinfection of microorganisms by use of electrochemically regenerated periodate," Appl. Environ. Microbiol. 71, 6410-6413 (2005).

${ }^{20} \mathrm{M}$. Beppu, H. Ochiai, and K. Kikugawa, "Macrophage recognition of periodate-treated erythrocytes: Involvement of disulfide formation of the erythrocyte membrane proteins," BBA Biomembr. 979, 35-45 (1989).

${ }^{21}$ K. P. Drees, M. Abbaszadegan, and R. M. Maier, "Comparative electrochemical inactivation of bacteria and bacteriophage," Water Res. 37, 2291-2300 (2003).

${ }^{22}$ H. F. Diao, X. Y. Li, J. D. Gu, H. C. Shi, and Z. M. Xie, "Electron microscopic investigation of the bactericidal action of electrochemical disinfection in comparison with chlorination, ozonation and Fenton reaction," Process Biochem. 39, 1421-1426 (2004).

${ }^{23}$ M. Mascia, A. Vacca, and S. Palmas, "Electrochemical treatment as a pre-oxidative step for algae removal using Chlorella vulgaris as a model organism and BDD anodes," Chem. 
Eng. J. 219, 512-519 (2013).

${ }^{24}$ Y. Long, J. Ni, and Z. Wang, "Subcellular mechanism of Escherichia coli inactivation during electrochemical disinfection with boron-doped diamond anode: A comparative study of three electrolytes," Water Res. 84, 198-206 (2015).

${ }^{25}$ X. Huang, Y. Qu, C. A. Cid, C. Finke, M. R. Hoffmann, K. Lim, and S. C. Jiang, "Electrochemical disinfection of toilet wastewater using wastewater electrolysis cell," Water Res. 92, 164-172 (2016).

${ }^{26} \mathrm{P}$. V. Nidheesh, M. Zhou, and M. A. Oturan, "An overview on the removal of synthetic dyes from water by electrochemical advanced oxidation processes," Chemosphere 197, 210-227 (2018).

${ }^{27}$ I. Sirés, E. Brillas, M. A. Oturan, M. A. Rodrigo, and M. Panizza, "Electrochemical advanced oxidation processes: Today and tomorrow. A review," Environ. Sci. Pollut. Res. 21, 8336-8367 (2014).

${ }^{28}$ M. Cho, J. Kim, J. Y. Kim, J. Yoon, and J. H. Kim, "Mechanisms of Escherichia coli inactivation by several disinfectants," Water Res. 44, 3410-3418 (2010).

${ }^{29}$ M. A. Oturan and J. J. Aaron, "Advanced oxidation processes in water/wastewater treatment: Principles and applications. A review," Crit. Rev. Environ. Sci. Technol. 44, 25772641 (2014).

${ }^{30}$ C. Zhang, Y. Jiang, Y. Li, Z. Hu, L. Zhou, and M. Zhou, "Three-dimensional electrochemical process for wastewater treatment: A general review," Chem. Eng. J. 228, 455-467 (2013).

${ }^{31}$ B. P. Chaplin, "The Prospect of Electrochemical Technologies Advancing Worldwide Water Treatment," Acc. Chem. Res. 52, 596-604 (2019).

${ }^{32}$ F. C. Walsh and C. Ponce de León, "Progress in electrochemical flow reactors for laboratory and pilot scale processing," Electrochim. Acta 280, 121-148 (2018).

${ }^{33}$ M. Sillanpää, M. C. Ncibi, and A. Matilainen, "Advanced oxidation processes for the removal of natural organic matter from drinking water sources: A comprehensive review," J. Environ. Manage. 208, 56-76 (2018).

${ }^{34}$ B. C. Hodges, E. L. Cates, and J. H. Kim, "Challenges and prospects of advanced oxidation water treatment processes using catalytic nanomaterials," Nat. Nanotechnol. 13, 642-650 (2018).

${ }^{35}$ R. Dewil, D. Mantzavinos, I. Poulios, and M. A. Rodrigo, "New perspectives for Advanced 
Oxidation Processes," J. Environ. Manage. 195, 93-99 (2017).

${ }^{36} \mathrm{~W}$. Gottardi, "Iodine as disinfectant," in Iodine Chemistry and Applications, edited by T. Kaiho (John Wiley \& Sons Incorporated, 2014).

${ }^{37} \mathrm{~W}$. Gottardi, "Iodine and disinfection: Theoretical study on mode of action, efficiency, stability, and analytical aspects in the aqueous system," Arch. Pharm. 332, 151-157 (1999).

${ }^{38}$ G. Mcdonnell and A. D. Russell, "Antiseptics and disinfectants: Activity, action, and resistance," Clin. Microbiol. Rev. 12, 147-179 (1999).

${ }^{39}$ D. T. Jiang, N. Chen, L. Zhang, K. Malgorzata, G. Wright, R. Igarashi, D. Beauregard, M. Kirkham, and M. McKibben, "XAFS at the Canadian Light Source," AIP Conf. Proc. 882, 893-895 (2007).

${ }^{40}$ B. Ravel and M. Newville, "ATHENA, ARTEMIS, HEPHAESTUS : data analysis for X-ray absorption spectroscopy using IFEFFIT," J. Synchrotron Radiat. 12, 537-541 (2005).

${ }^{41}$ V. Schmalz, T. Dittmar, D. Haaken, and E. Worch, "Electrochemical disinfection of biologically treated wastewater from small treatment systems by using boron-doped diamond (BDD) electrodes - Contribution for direct reuse of domestic wastewater," Water Res. 43, 5260-5266 (2009).

${ }^{42}$ S. Chen, W. Hu, J. Hong, and S. Sandoe, "Electrochemical disinfection of simulated ballast water on PbO2/graphite felt electrode," Mar. Pollut. Bull. 105, 319-323 (2016).

${ }^{43}$ C. Heim, M. Ureña de Vivanco, M. Rajab, E. Müller, T. Letzel, and B. Helmreich, "Rapid inactivation of waterborne bacteria using boron-doped diamond electrodes," Int. J. Environ. Sci. Technol. 12, 3061-3070 (2015).

${ }^{44}$ W. A. Reed, I. May, F. R. Livens, J. M. Charnock, A. P. Jeapes, M. Gresley, R. M. Mitchell, and P. Knight, "Xanes fingerprinting of iodine species in solution and speciation of iodine in spent solvent from nuclear fuel reprocessing," J. Anal. At. Spectrom. 17, 541-543 (2002).

${ }^{45}$ Y. S. Shimamoto, T. Itai, and Y. Takahashi, "Soil column experiments for iodate and iodide using k-edge xanes and hplc-icp-ms," J. Geochem. Explor. 107, 117-123 (2010).

${ }^{46} \mathrm{~N}$. Yamaguchi, M. Nakano, R. Takamatsu, and H. Tanida, "Inorganic iodine incorporation into soil organic matter: evidence from iodine k-edge x-ray absorption near-edge structure," J. Environ. Radioact. 101, 451-457 (2010).

${ }^{47}$ A. J. Bard and L. R. Faulkner, Electrochemical methods: fundamentals and applications, 
2nd ed. (Wiley, New York, 2000).

${ }^{48} \mathrm{R}$. H. Wopschall and I. Shain, "Effects of Adsorption of Electroactive Species in Stationary Electrode Polarography," Anal. Chem. 39, 1514-1527 (1967).

${ }^{49}$ R. H. Wopschall and I. Shain, "Adsorption Characteristics of the Methylene Blue System Using Stationary Electrode Polarography," Anal. Chem. 39, 1527-1534 (1967).

${ }^{50}$ R. S. Kumar, S. Sornambikai, N. S. Karthikeyan, K. Sathiyanarayanan, and A. Senthil, "A Simple Colorimetric Screening of Nitrite Using Iodide in an Acidic pH Solution," Austin J. Anal. Pharm. Chem. 1, 1-3 (2014).

${ }^{51}$ G. Dryhurst and P. J. Elving, "Electrooxidation of Halides at Pyrolytic Graphite Electrode in Aqueous and Acetonitrile Solutions," Anal. Chem. 39, 606-615 (1967).

${ }^{52}$ E. Cho, A. Perebikovsky, O. Benice, S. Holmberg, M. Madou, and M. Ghazinejad, "Rapid iodine sensing on mechanically treated carbon nanofibers," Sensors 18, 1486 (9pp)1486 (9pp) (2018).

${ }^{53}$ L. M. Dané, L. J. J. Janssen, and J. G. Hoogland, "The iodine/iodide redox couple at a platinum electrode," Electrochim. Acta 13, 507-518 (1968).

${ }^{54}$ A. Bard, R. Parson, and J. Jordon, Standard potentials in aqueous solutions (M. Dekker, New York, 1985).

${ }^{55} \mathrm{M}$. Torimura, K. Kano, T. Ikeda, M. Goto, and T. Ueda, "On-line electrochemical detection of carbohydrates coupled with the periodate oxidation," J. Chromatogr. A 790, 1-8 (1997). 